\title{
Especial
}

\section{ILUMINAÇÃO CÊNICA E DESOBEDIÊNCIAS DE GÊNERO}

\author{
SCENIC LIGHTING AND GENDER DISOBEDIENCE
}

ILUMINACIÓN ESCÉNICA Y DESOBEDIENCIAS DE GÉNERO

\section{Dodi Tavares Borges Leal}

Dodi Tavares Borges Leal Doutora em Psicologia Social pelo Instituto de Psicologia da Universidade de São Paulo e licenciada em Artes Cênicas pela Escola de Comunicações e Artes da Universidade de 


\section{Resumo}

Este texto apresenta alguns achados de pesquisa de doutorado recémconcluída sobre transgeneridades e recepção teatral. Um dos aspectos nevrálgicos dos resultados da investigação é o potencial performativo da luz cênica como força lírica de expressão das visualidades de desobediências de gênero. A partir da crítica ao paradigma patológico de "transexualidade", que reduz a amplitude das transgeneridades à modificação corporal, aventamos a corruptela "luzvesti" (luz + travesti) como operadora do aparato estético da iluminação cênica sobre desobediências de gênero. Nessa mesma direção, embasando-nos em uma perspectiva contrassexual, a ideia de diversidade sexual representada por siglas é posta em xeque em seu produtivismo cardapialista, monossexual e em escala. A partir da análise dos efeitos de luz das encenações $A$ demência dos touros (Cia. Teatro do Perverto, 2017) e As 3 Uiaras de SP City (Laboratório de Técnica Dramática, 2018), tendo ambas abordado as transgeneridades como problemática urbana, pretende-se neste artigo indicar os aportes da iluminação cênica ao redimensionamento teórico dos estudos de gênero a partir das visualidades. Assim, o que se entende por autodesignação identitária em função do desejo ou de práticas sexuais passa a ser tensionado com processos subjetivos e sociais de performatividade e de recepção contrassexuais, percebendo a luz como um elemento de desenho espacial do gênero. A iluminação como traje de cena (vestir-se de luz) é então vista como uma possível resultante espacial de desobediência de gênero entre a dramaturgia da luz e a atuação da recepção teatral.

Palavras-chave: Iluminação cênica, Transgeneridades, Contrassexualidade, Performance de gênero, Recepção teatral. 


\section{Abstract}

This text presents some findings of a recently concluded doctoral research on transgenderity and theatrical reception. One of the neuralgic aspects of the research results is the performative potential of scenic light as a lyrical force of expression of the visualities of gender disobedience. From the critique of the pathological paradigm of "transexuality", which reduces the amplitude of the transgenerities to the body modification, we propose the corrupted term "luzvesti" (luz/lighting + transvestite) as operator of the aesthetic apparatus of the scenic lighting on disobediences of gender. In the same direction, based on a contrassexual perspective, the idea of sexual diversity represented by acronyms is put in check in its carte/menu characteristics, and its monosexual and scale produtivism. From the analysis of the light effects of the plays A demência dos touros / The dementia of the bulls (Cia Teatro do Perverto, 2017) and As 3 Uiaras the SP City / The 3 Uiaras from SP City (Laboratory of Dramatic Technique, 2018), both of which approached transgenerities as an urban issue, this article indicates the contributions of the scenic lighting to the theoretical resizing of the studies of gender from the visualities. Thus, what is understood by self-identification as a function of desire or sexual practices become tensioned with subjective and social processes of contrassexual performativity and reception, perceiving light as an element of spatial design of gender. Lighting as a costume of the scene (light dressing) is then seen as a possible spatial result of gender disobedience between the dramaturgy of light and the performance of theatrical reception. Keywords: Stage lighting, Transgenderity, Contrassexuality, Gender performance, Theatrical reception. 


\section{Resumen}

Este texto presenta algunos hallazgos de investigación recién concluida sobre transgeneridades y recepción teatral. Uno de los aspectos neurálgicos de los resultados de la investigación es el potencial performativo de la luz escénica como fuerza lírica de expresión de las visualidades de desobediencias de género. A partir de la crítica al paradigma patológico de "transexualidad", que reduce la amplitud de las transgeneridades a la modificación corporal, aventamos el termo corrompido "luzvesti" (luz + travesti) como operador del aparato de la iluminación escénica sobre desobediencias de género. En esa misma dirección, basándonos en una perspectiva contrassexual, la idea de diversidad sexual representada por siglas/acrónimos es puesta en jaque en su productivismo cardapialista, monosexual y en escala. A partir del análisis de los efectos de luz de las obras $A$ demência dos touros / La demencia de los toros (Cia. Teatro del Perverto, 2017) y As 3 Uiaras de SP City / Las 3 Uiaras de SP City (Laboratorio de Técnica Dramática, 2018), habiendo ambas abordado las transgeneridades como problemática urbana, se pretende en este artículo indicar los aportes de la iluminación escénica al redimensionamiento teórico de los estudios de género a partir de las visualidades. Así, lo que se entiende por autodesignación identitaria en función del deseo o de prácticas sexuales pasa a ser tensado con procesos subjetivos y sociales de performatividad y de recepción contrassexuales, percibiendo la luz como un elemento de diseño espacial del género. La iluminación como traje de escena (vestirse de luz) es entonces vista como una posible resultante espacial de desobediencia de género entre la dramaturgia de la luz y la actuación de la recepción teatral.

Palabras clave: Iluminación escénica, Transgeneridades, Contrassexualidad, Performance de género, Recepción teatral.

\section{Introdução}

A busca por recursos das visualidades cênicas (cenografia, maquiagem, luz etc.) para operar a expressividade de desobediências de gênero se fundamenta na derrocada da tipificação identitária assentada em processos de patologização. A interveniência de modos de existir nos quais as configurações de 
gênero rompem com a cisnormatividade requer, por sua vez, um aparato performativo no sentido de delinear as falhas de projetos dramáticos sobre o corpo.

Nesse sentido, o paradigma da "transexualidade", que restringe a transição de gênero à modificação corporal, é posto em xeque, já que os processos das transgeneridades prescindem da genitalização do gênero e de quaisquer outros modos de intervenção cirúrgica. Ao passo que a noção de desobediência de gênero nos remete a processos subjetivos e sociais (OLIVEIRA, 2017), a experiência transgênera é cada vez mais compreendida como sendo da ordem da performatividade em fricção com os processos de recepção. Ora, é justamente nesse jogo entre o que se performa em termos de gênero, de um lado, e as leituras de gênero, de outro, que se dá a ocorrência de mecanismos estéticos nos quais a corporalidade desenha o espaço em contornos de gênero.

A iluminação cênica, enquanto área fundamental das visualidades teatrais, se nos apresenta como uma possível linguagem de gênero. No entanto, os oximoros visuais de luz e sombra são muito mais que gradientes de tonalidade de gênero. As possibilidades de configuração das desobediências de gênero em efeitos de luz dão ensejo para a assimilação visual de sua espacialidade cênica (LEAL, 2018a). Por sua vez, a intrincada relação entre os modos simbólicos e sensíveis da comunicação estética (BOAL, 2009) ganha na luz cênica um campo instigante de elaboração da percepção de gênero para além do caráter informativo no qual se assentam as normatividades sociais. Ou seja, em vez de reforço a um paradigma dramático de pensamento simbólico sobre as identidades de gênero (homem e mulher), a iluminação cênica parece nos aproximar de uma categoria sensível de expressão estética na qual a força lírica da luz remete a modelos visuais de performance de gênero (cis e trans).

Este artigo pretende apontar alguns elementos da performatividade da luz enquanto aparato sensível de expressão estética das transgeneridades. Para tanto, além dos efeitos de luz destacados de duas encenações teatrais recentes, retomamos brevemente elementos críticos nos quais as dissidências sexuais e as desobediências de gênero parecem se opor ao produtivismo da diversidade e à patologização contida na noção de "transexualidade". Antes dos apontamentos específicos sobre as resultantes de gênero da dramaturgia da luz e da atuação da recepção teatral, levantaremos alguns aspectos 
teóricos e práticos sobre os processos de gênero em que uma abordagem contrassexual nos permitirá compreender as dimensões visuais performativas de desobediências de gênero negligenciadas no uso de siglas identitárias.

\section{Dissidências sexuais e desobediências de gênero}

Pretendemos aqui apresentar algumas reflexões acerca de como os limites dos processos sociais de sexualidade e de gênero baseados num ideário produtivista de diversidade ensejam a pesquisa das visualidades cênicas como linguagem de expressão de dissidências sexuais e de desobediências de gênero. Nesse sentido, tanto os ganhos como as falhas identitárias contidas neste percurso herdado do século $X X$, marcado pela hegemonia das sexualidades no espectro cisnormativo, ensejam hoje o sublinhamento das interações subjetivas e sociais da performatividade de gênero com a recepção de gênero.

Um primeiro aspecto a se abordar a respeito da noção de diversidade é a sua estigmatização sexual. De fato, a luta por reconhecimento de práticas sexuais não normativas foi um traço extremamente significativo da revolta de Stonewall, em Nova York, em 1969. Como legado, muitos direitos sociais passaram a ser auferidos e reclamados desde então (apesar de sua falibilidade devido ao reincidente conservadorismo). Ora, o uso de siglas para remeter a grupos de resistência sexual passou a se justapor, na legenda de letrinhas, a formas performativas de gênero contestatórias da cisnormatividade. Gerouse aí um quiproquó que ainda hoje é de difícil desembaraçamento, ou seja, a noção de que o sujeito ou contesta a normatividade sexual ou contesta a normatividade de gênero; e mais: de que se fazendo uma contestação, não se faz a outra, como se fossem excludentes. As siglas, artefatos de resistência, passaram assim a ter uma naturalização em seu uso comum, uma vez que qualificam a diversidade não apenas como uma opção entre várias (cujo desdobramento nomearemos de cardapialismo) mas, sobretudo, por fundamentarem-na em sua sexonormatividade, ou seja, em função de sua funcionalidade sexual. Uma consequência que indica a falência desse modo de operar é o negligenciamento das performances de gênero (cis e trans) subjacente a quaisquer formas de sexualidade, tanto hegemônicas quanto de resistência. 
O aburguesamento da luta por direitos sexuais se expressou durante as últimas décadas pela prevalência do casamento monogâmico com divisão de bens enquanto centralidade de pauta política. Simultaneamente pouca atenção se deu ao contínuo genocídio da população trans, que culmina, ainda em 2018, em alcançar a expectativa de vida de 36 anos. Muito mais do que debater o método estatístico ou a linearidade científica desse dado, interessa-nos perceber como os atravessamentos entre os assuntos de sexualidade e de gênero ainda são pouco explorados do ponto de vista crítico e estético. Um simulacro desse enredamento está na subsistência de formas transgêneras nas existências bixas e sapatônicas, ora exclusivamente ligadas a práticas sexuais quando seus conteúdos subjetivos e sociais remetem nitidamente a performatividades gênero-desobedientes.

O próprio não reconhecimento de que bixa e sapatão são formas trans (e são!) tem que ver com a reincidência da categoria "transexual," criada pela psiquiatria para tipificação de doença mental, e pela epidemiologia para controle social de doenças sexualmente transmissíveis (LEAL, 2018b). Na versão "transexual" das transgeneridades, a ficção patológica de disforia de gênero assenta-se não apenas na ideia do descontentamento do sujeito com o próprio corpo mas, sobretudo, na de que é necessário algum tipo de modificação corporal (genital, dos seios, hormonização etc.) para categorizar alguém como trans. Daí nasce não apenas a noção equivocada de que nós, travestis, não somos trans mas, principalmente, a necessidade de controle biopolítico das diferenças entre os corpos trans no sentido de se legitimar quem é mais trans do que quem - obviamente num paradigma cisnormativo.

Inspiradas no Manifesto contrassexual (PRECIADO, 2014), propomos literalmente a substituição do termo diversidade por dissidências sexuais e desobediências de gênero - não apenas no sentido de apontar o fracasso das siglas enquanto processo identitário, cujos pontos críticos serão indicados sumariamente a seguir mas, principalmente, com o intuito de rascunhar formas de combater a apropriação do capital sobre a noção de diversidade, que acaba por se manifestar em meios de controle. Não é à toa que a objetificação de formas não hegemônicas de sexualidade e gênero guarda consigo a abjeção como processo psicossocial interdependente (LEAL; DENNY, 2018). Objetas e abjetas, as corporalidades dissidentes e desobedientes ganham 
com o termo "diversidade" a higienização necessária para se inserirem eficientemente nos meios de produção e consumo do capital.

$\mathrm{Na}$ tese Performatividade transgênera: equações poéticas de reconhecimento recíproco na recepção teatral (LEAL, 2018b) defino três formas problemáticas nas quais se assentam o histórico de formatação do gosto, de controle sobre o corpo trans e de luta pelas siglas, as quais corroboraram historicamente a prevalência de direitos sexuais sem combater a cisnormatividade. Nesse sentido, comento a seguir o cardapialismo, a monossexualidade e a escala/régua e, na sequência, parto para a observação das visualidades cênicas enquanto possibilidades performativas e de recepção das desobediências de gênero, tendo a especificidade da luz como linguagem investigativa.

A noção de cardapialismo sintetiza a estigmatização do gosto enquanto forma funcional de identificação classificatória de uso e descarte dos corpos; enquanto se privilegia o gosto, pouco se percebe sobre as lacunas do não gostar. O que o cardapialismo das siglas sustenta é uma verdadeira naturalização do gosto e do não gosto sobre os corpos, pouco levando em conta o processo social de formação dessas preferências. Mas, mais do que isto, toda sigla é uma tentativa de legitimar preconceito: há nas siglas a ideia de que podemos gostar de alguns corpos e de que outros corpos não são gostáveis a partir do momento em que alguém se apresenta em uma ou outra categoria. O sujeito aqui não é apenas um cardápio sexual, mas faz os outros sujeitos de cardápio sexual.

A monossexualidade se soma ao cardapialismo no sentido de haver uma naturalização de que se deve gostar de um tipo de gênero ou de outro. Historicamente vinculada às categorias de bissexualidade ou pansexualidade, a monodissidência sexual é uma configuração que procura romper com a monossexualidade sobretudo no que concerne à ideia de que esta é uma orientação individual do desejo. Ora, a égide monogâmica das práticas sexuais se associa dramaticamente à monossexualidade, quase como expectativas mutuamente operantes sobre os corpos. $\mathrm{O}$ que a sexualidade das siglas negligencia, além dos processos performativos de gênero, é que todos os corpos são gostáveis e que o não gosto é sempre um preconceito 
construído ao longo da vida dos sujeitos em processos sociais de dominação e de resistência.

Nomeamos de escala/régua o controle biopolítico sobre os corpos trans que se expressa nas últimas décadas na síntese "TT". Essa configuração brasileira (interdependente de outros países da América Latina) que se dá na formulação "pessoas trans e travestis" diferencia as transgeneridades em função da maior ou menor adequação ao extremamente problemático e falido processo transexualizador. Ainda que haja diferenças históricas no uso dos termos, estes referem-se ao mesmo fenômeno: trans são travestis, e travestis são trans. A reincidente diferenciação em escala se assemelha a uma parametrização das transgeneridades em uma régua para ver quem é mais trans do que quem. Como em uma sugestiva associação ao colorismo como controle biopolítico sobre os corpos negros no Brasil, a escala/régua não apenas fundamenta e naturaliza a cisnormatividade, mas sofistica o controle do Estado sobre os corpos trans. Por fim, a justaposição do termo "sexual" ao radical "trans" não apenas coroou durante muitos anos a genitalização das transgeneridades mas, sobretudo, evitou destacar que ser trans é uma questão de gênero e, ainda, que os processos de gênero se dão em equações complexas de visualidade entre a performance e a recepção dos corpos em sua espacialidade.

\section{Performatividade da luz e transgeneridades}

Comporemos aqui a indicação de alguns efeitos de luz das encenações A demência dos touros (Cia. Teatro do Perverto, 2017) e As 3 Uiaras de SP City (Laboratório de Técnica Dramática, 2018). Tanto uma quanto outra obra desdobraram cenicamente as transgeneridades como problemática urbana. Tendo em consideração as limitações levantadas anteriormente, objetiva-se aqui verificar como os estudos de gênero podem ser redimensionados teoricamente quando levamos em conta elementos expressivos da comunicação visual. Assim, verifiquemos algumas das possibilidades dramatúrgicas da luz em sua sugestividade de experiência de gênero junto à recepção teatral. 
Em A demência dos touros, a manipulação das fontes e dos controles de luz em cena pelos/as atores/atrizes se deu em concomitância com o olhar crítico sobre as modulações de gênero do corpo trans postas em cena. Na encenação percebeu-se que a visualidade dos aspectos sociais de gênero, por meio da luz cênica, pode se configurar de várias formas. Um elemento estético relevante da iluminação cênica dessa montagem se deu em torno de seu caráter expressionista que, diferentemente de uma iluminação mais naturalista, não tinha como foco valorizar o efeito atmosférico da luz (CAMARGO, 2000). Nesse sentido, o percurso criativo da luz nessa montagem se fez menos com o intuito imitativo da realidade e mais com a intenção de seletividade e sobressalência de algum aspecto cênico relativo à materialidade do gênero.

O potencial performativo da luz (LUCIANI, 2012), caracterizado pela capacidade da poética da luz de instaurar-se cenicamente enquanto um fazer, um acontecimento, tornou-se nessa encenação um aparato concreto de percepção dos traços líricos do gênero junto à recepção teatral. Nesse sentido, a produção performativa da luz nos aproxima da própria propositividade do grupo diante do efeito estético proporcionado aos/às espectadores/as no sentido da provocação já antecipada no próprio processo criativo (DESGRANGES, 2012; DESGRANGES; SIMÕES, 2017). A iluminação cênica enquanto linguagem de pesquisa expressiva e de percepção das transgeneridades, a partir de uma luz onírica, revelou-se enquanto elemento perspicaz de desenho de sutilezas íntimas. Um exemplo desse recurso, demonstrado na Figura 1, foi a inserção de luzes pisca-pisca em um repolho, indicando o bebê trans e seu aspecto multicor. Por outro lado, também se trabalhou com um efeito mais cortante no que se refere aos rasgos nas paredes inscritos por lâmpadas fluorescentes e aos entulhos iluminados em um carrinho de mão, ambos trazendo a noção de muro e de cerceamento espacial do lugar de pertencimento e de não pertencimento de pessoas trans na cidade ficcional. Diga-se de passagem que, em determinado momento da encenação, ambos os efeitos se conectam quando a protagonista usa o carrinho de mão como berço de seu bebê trans. Além desses efeitos, houve uma reincidente ambientação embranquecedora do espaço cênico pela escolha do tipo de lâmpada e por sua cor asséptica, remetendo o público à espacialidade clínica do contexto médico, que manipula a corporalidade trans com processos hormonais, entre outros. 
Figura 1 - A demência dos touros

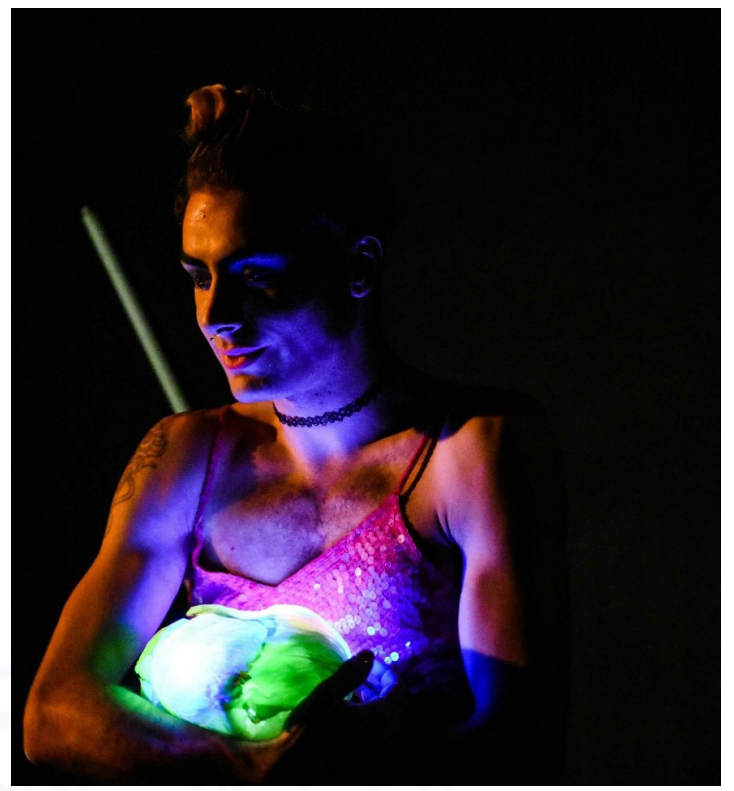

Foto: Karina Lumina (2017)

Figura 2 - A demência dos touros

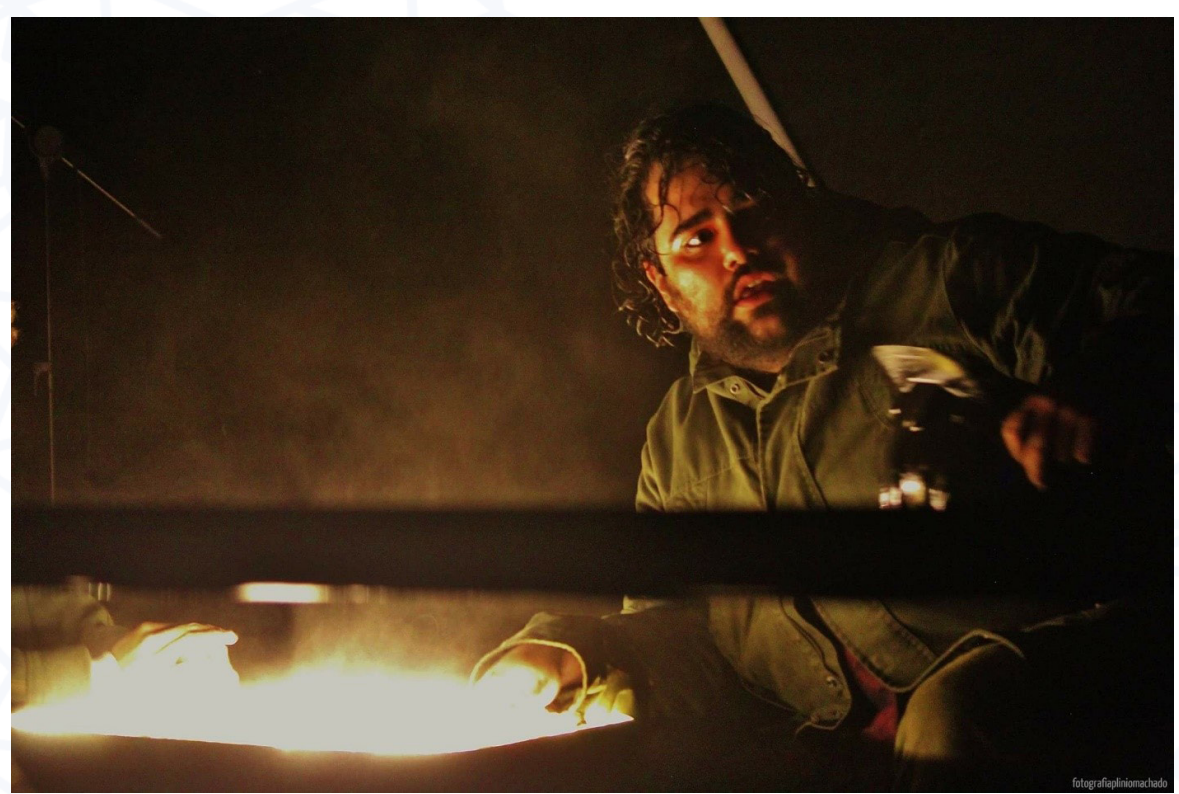

Foto: Plínio Machado (2017)

Uma utilização recorrente da luz cênica no espetáculo foi o de desenho espacial da opressão de gênero. Na Figura 2 vê-se um operário que, com um carrinho de mão iluminado, indica o percurso narrativo de segregação que se cria na peça a partir das ações de construção de um muro que divide na urbanidade as pessoas trans das pessoas cis. O entulho como fonte de luz dá tom à tensão espacial das transgeneridades em ambientes sociais cisnormativos. 
Ainda sobre o desenho espacial de gênero, tendo a luz como fator de divisão em muro ou de rasgo do espaço social, há na Figura 3 outra incidência deste efeito, agora mostrando a divisão que também se dá entre o saber médico predominantemente cisgênero sobre o corpo transgênero. Neste sentido, a luz como que revela o espaço cênico como um sintoma da dominação de gênero: a luz como transgeneridades que brotam em espaços não convidativos, murados em ideias ou em concreto.

Figura 3 - A demência dos touros

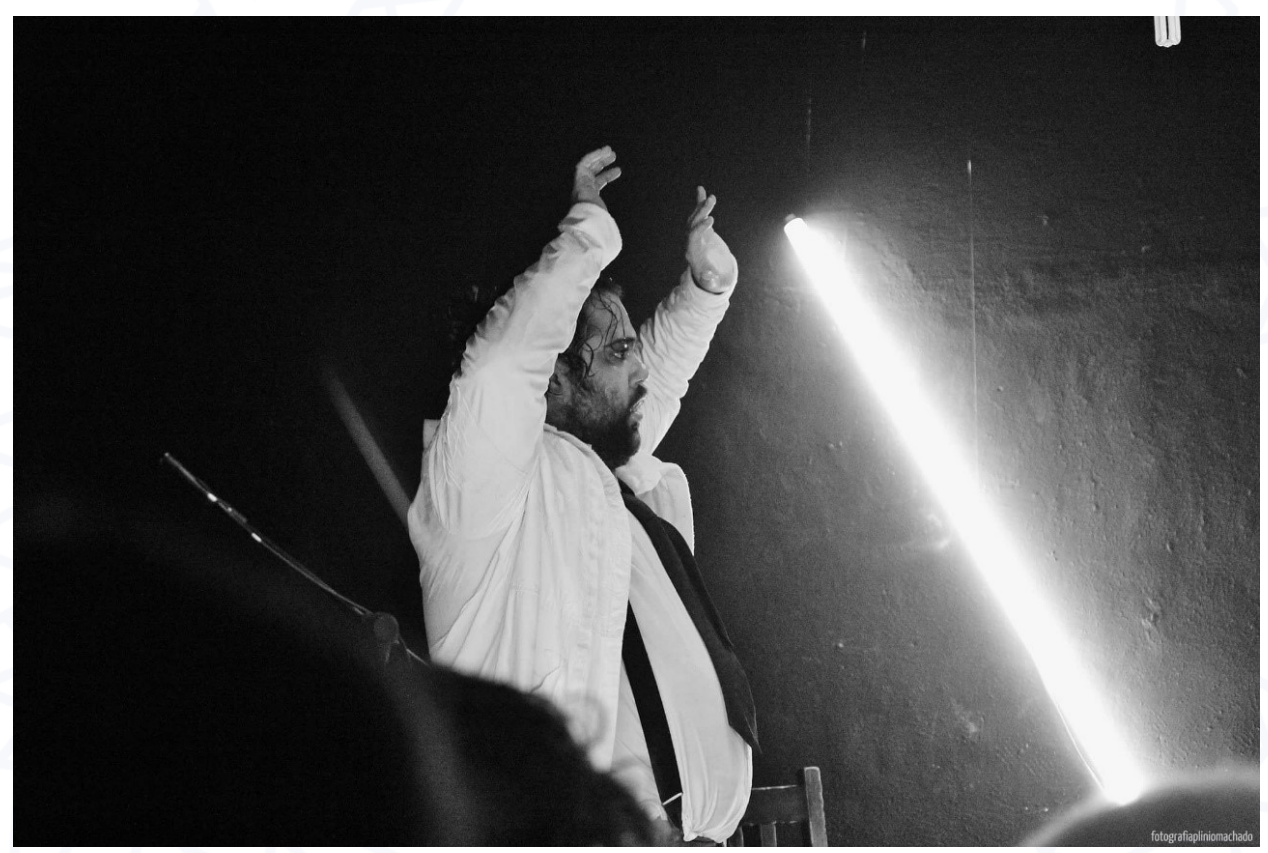

Foto: Plínio Machado (2017)

Na Figura 4 vê-se a manipulação da lâmpada como uma operação trans. A mudança de luz é uma questão transgênera. De fato, o espetáculo termina com esta nova lâmpada, que, por possuir um eletromagnetismo interior, transforma o espaço anterior e indica um vetor para formas de gênero não apreendidas pelos sistemas hegemônicos. Percebe-se neste gesto derradeiro da peça a necessidade de desnaturalização atmosférica da luz cisnormativa. A luz cisnormativa, sendo a luz do ambiente, que dá uma visibilidade indisconfiável aos elementos visivos, é aqui posta em xeque não apenas para que se perceba a emanação iluminante dos objetos tendo em vista suas diferenças topográficas e refratárias, mas, principalmente, para tornar o ambiente social de gênero como um fator de experimentação espacial da luz cênica.

Figura 4 - A demência dos touros 


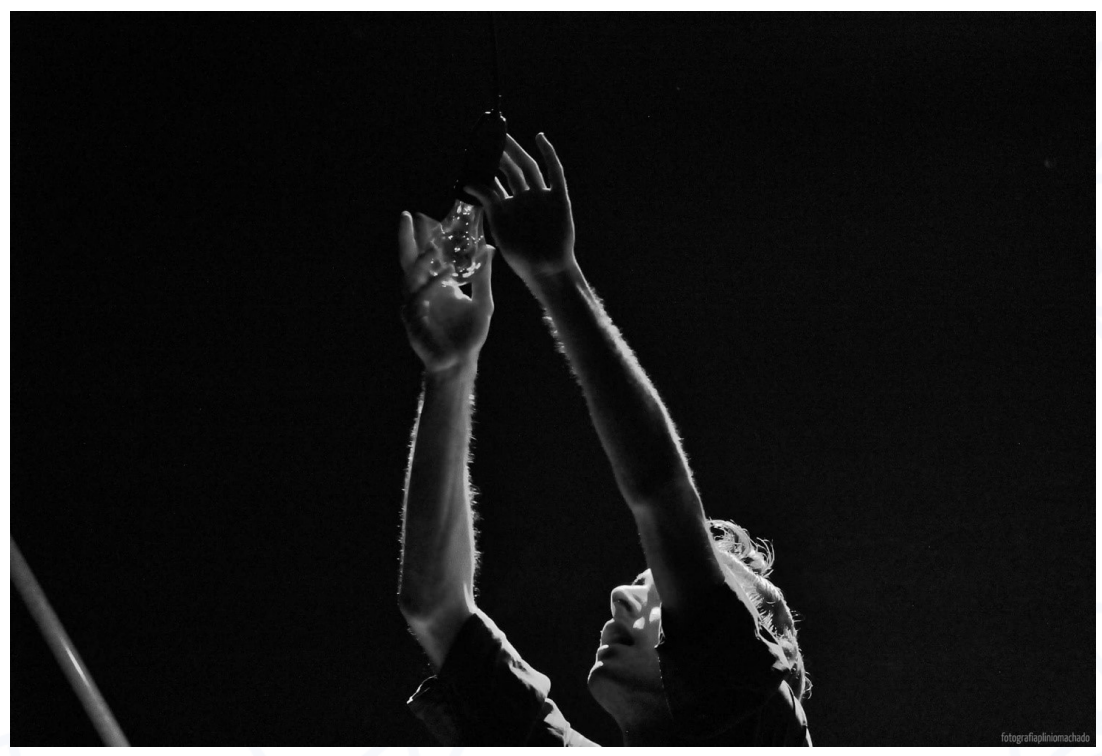

Fonte: Plínio Machado

Em As 3 Uiaras de SP City, a iluminação cênica teve papel fundamental para o desenho da espacialidade das transgeneridades na urbanidade. Nessa encenação, a cidade de São Paulo (com o irônico codinome "SP City" pronunciado com o sotaque ítalo-paulistano) é o cenário onde, no fim da década de 1970 e durante toda a década de 1980, por meio da operação policial Tarântula, travestis eram presas e torturadas. A espacialidade do gênero como modo de luz nessa peça foi tratada fundamentalmente com o desenho da rua projetado pelos refletores em posição perpendicular à boca de cena. Em um primeiro momento, uma luz de fundo criava a ideia de rua vertical, diante da recepção; em um segundo momento, uma luz lateral criava a ideia de rua horizontal, diante da recepção; e, em um terceiro momento, ambas compunham a esquina. A genialidade de configurar a esquina enquanto aparato de expressão a partir da linguagem da luz cênica tem um efeito de memória em que a iluminação é uma espécie de espacialização do transporte onírico da recepção para uma aventura de gênero no tempo, como se vê na Figura 7. Além da esquina como marca do ponto de prostituição, a iluminação cênica nessa encenação é entremeada por outro aparato expressivo instigante, que é a filmagem e a projeção dos olhos das atrizes em vários quadros, como se vê na Figura 5. Não encontramos aí apenas o efeito de luz inerente ao dos próprios olhos projetados no espaço, mas também a sugestividade de vigilância e controle que a iluminação pode ter sobre os processos de gênero dos corpos no espaço.

Figura 5 - As 3 Uiaras de SP City 


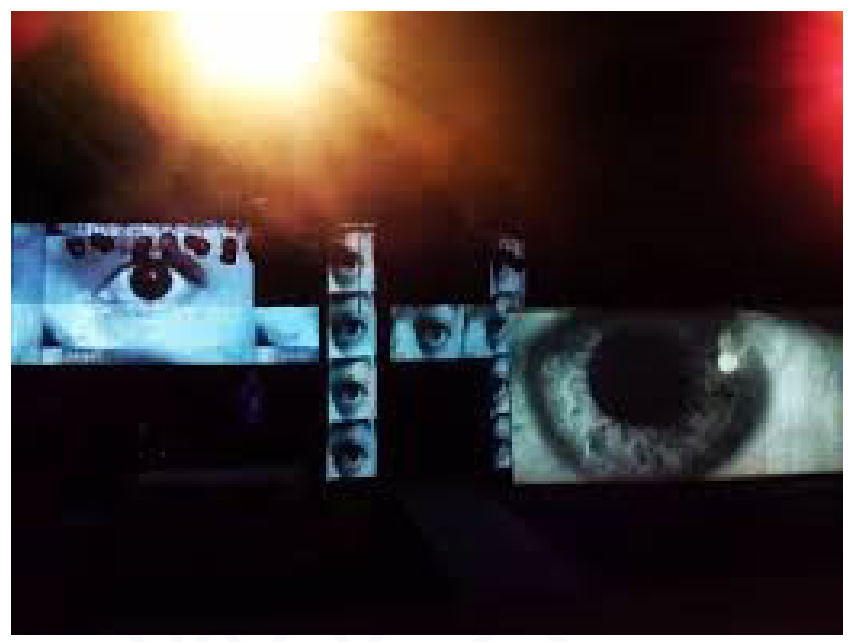

Foto: Renato Mangolin (2018)

Por fim, há um outro efeito de luz trabalhado na encenação para expressar desobediências de gênero na conjugação da iluminação com a musicalidade. Com a participação de duas cantoras no elenco, Verónica Valenttino e Danna Lisboa, o desenho de luz no espaço ganhou forma codependente da euforia de gênero suscitada na disposição em formato de show de algumas cenas. Importante destacar que, simultaneamente aos contornos de luz da resistência das transgeneridades no espaço social, essa encenação não se furtou de indicar a paradoxalidade visual das sombras, sobretudo no que se refere à presença opressora dos policiais, como se vê na Figura 6 .

Figura 6 - As 3 Uiaras de SP City

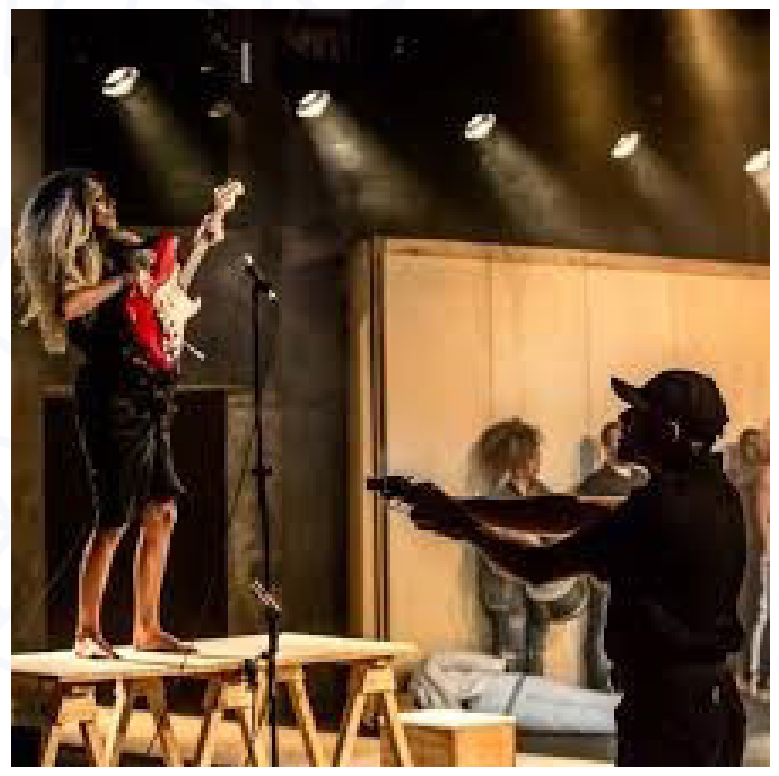

Foto: Renato Mangolin (2018)

Figura 7 - As 3 Uiaras de SP City 


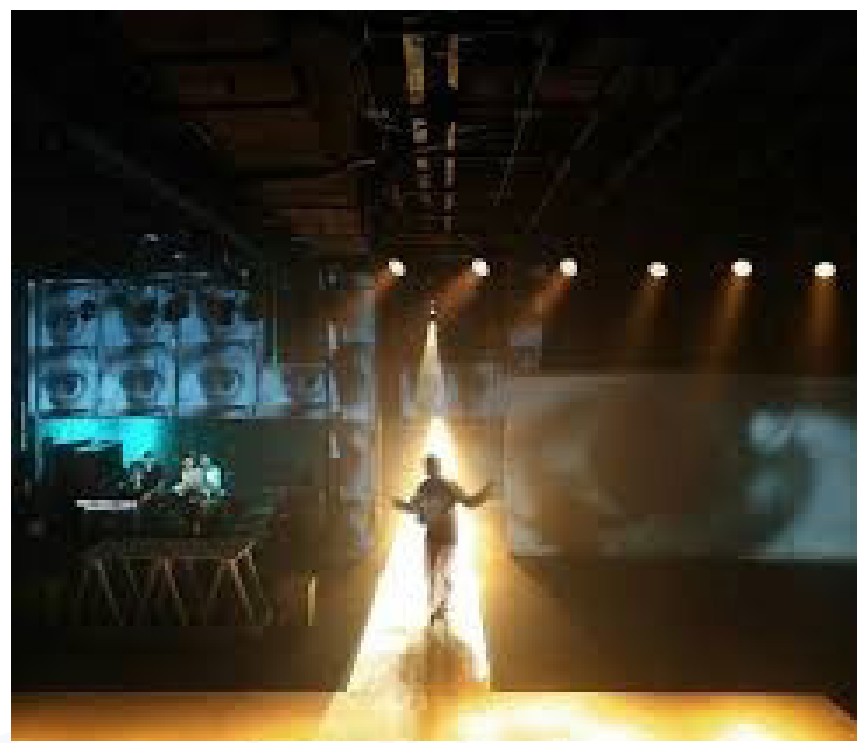

Foto: Renato Mangolin (2018)

\section{Resultantes de gênero da dramaturgia da luz e da atuação da recepção teatral}

Discutir a iluminação cênica a partir dos estudos de gênero requer a consideração do potencial performativo da luz enquanto desenho da espacialidade teatral. No entanto, aqui propusemos um pouco mais do que isso. Almejamos indicar um caminho de redimensionamento teórico dos estudos de gênero a partir das visualidades cênicas. Ao aventar os aspectos críticos contidos nas siglas, na noção de diversidade e na assunção patológica de "transexualidade", procuramos destacar alguns dos limites em que se encontra a luta por reconhecimento das dissidências sexuais e das desobediências de gênero para, então, empreendermos uma reflexão sobre as possibilidades da iluminação cênica enquanto pesquisa visual desses processos.

Verificamos que tanto a espacialidade do gênero como modo de luz quanto a espacialidade do gênero como modo de recepção se dão a partir de processos performativos. As provocações contrassexuais de releitura da diversidade buscando destacar as desobediências de gênero, por sua vez, ganham na visualidade cênica um encontro favorável de diálogo propositivo com a recepção. A corruptela "luzvesti" (luz + travesti), bem exemplificada na Figura 8, condensa o papel performativo da iluminação cênica de alterar a 
percepção da recepção sobre as desobediências de gênero. Transgeneridade é, sim, uma questão de luz! Nesse sentido, travestir, enquanto verbo, pode significar $o$ ato de vestir-se de luz - iluminação cênica expandindo gênero para além da cisnormatividade, de maneira desobediente.

Figura 8 - Verónica Valenttino

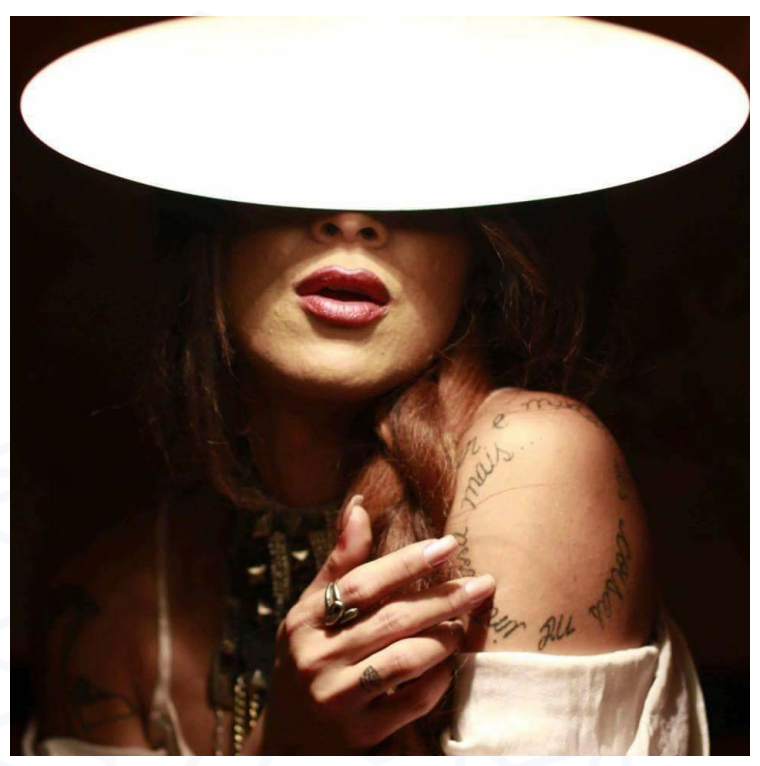

Foto: Ruan Padilha (2018)

\section{Referências}

BOAL, A. A estética do oprimido: reflexões errantes sobre o pensamento do ponto de vista estético e não científico. Rio de Janeiro: Garamond, 2009.

CAMARGO, R. G. Função estética da luz. Sorocaba: TCM Comunicação, 2000.

DESGRANGES, F. A inversão da olhadela: alterações no ato do espectador teatral. São Paulo: Hucitec, 2012.

DESGRANGES, F.; SIMÕES, G. (org.). 0 ato do espectador: perspectivas artísticas e pedagógicas. São Paulo: Hucitec, 2017.

LEAL, D. Luzvesti: iluminação cênica, corpomídia e desobediências de gênero. Salvador: Devires, 2018a.

Performatividade transgênera: equações poéticas de reconhecimento recíproco na recepção teatral. 2018. 534 f. Tese (Doutorado em Psicologia Social) - Instituto de Psicologia da Universidade de São Paulo, São Paulo, 2018b.

LEAL, D.; DENNY, M. (org.). Gênero expandido: performances e contrassexualidades. São Paulo: Annablume, 2018.

LUCIANI, N. Sobre a performatividade da luz. O Mosaico: revista de pesquisa em artes, Curitiba, n. 8, p. 87-101, jul./dez. 2012. 
OLIVEIRA, J. M. Desobediências de gênero. Salvador: Devires, 2017.

PRECIADO, P. Manifesto contrassexual: práticas subversivas de identidade sexual. Tradução Maria Paula Gurgel Ribeiro. São Paulo: n-1, 2014.

Recebido em 05/08/2018

Aprovado em 10/08/2018

Publicado em 25/10/2018 